\title{
Isolation and Characterization of Rat Schwannoma Neurite-promoting Factor: Evidence that the Factor Contains Laminin ${ }^{1}$
}

\author{
GEORGE E. DAVIS, ${ }^{2}$ MARSTON MANTHORPE, EVA ENGVALL, ${ }^{\star}$ AND SILVIO VARON
}

Department of Biology, School of Medicine, University of California, San Diego, La Jolla, California 92093 and *Cancer Research Center, La Jolla Cancer Research Foundation, La Jolla, California 92037

\begin{abstract}
Rat RN22 schwannoma cells in vitro release into their growth medium a macromolecular factor that, when bound to polyornithine-coated culture substrata, will stimulate neuritic regeneration from axotomized peripheral and central neurons. During the purification of this factor, the neurite-promoting activity co-purifies with laminin immunoreactivity as measured by an enzyme-linked immunoadsorbant assay. The purified factor has an immunoreactivity per milligram of protein similar to that of purified rat yolk sac tumor laminin. After sodium dodecyl sulfate-polyacrylamide gel electrophoresis (SDS-PAGE) under reducing conditions, the purified factor exhibits a major band at $\mathbf{2 0 0}$ kilodaltons (kD) and two minor ones at about 130 and $35 \mathrm{kD}$. The 200-kD band comigrates with the 200-kD band of purified rat laminin. After SDS-PAGE under non-reducing conditions, the rat schwannoma factor and rat laminin both exhibit a band in the 900KD range with the schwannoma factor band migrating slightly faster than the laminin one. The 200-kD (reducing conditions) and $900-\mathrm{kD}$ (non-reducing conditions) bands of both the schwannoma factor and laminin are stained by immunoblotting with antisera raised against rat and human laminin and against a partially purified preparation of the schwannoma factor. On immunoblots the $400-\mathrm{kD}$ band of laminin (a band not seen in the schwannoma factor preparation) also stains with all three antisera. When the antibodies from each of the three antisera are immobilized on protein A-agarose beads, the beads will completely remove from solution the neuritepromoting activities of both the schwannoma factor and laminin. Antibodies raised against rat laminin fail to block the neurite-promoting activity of the purified schwannoma factor but totally block that of rat laminin. In contrast, antibodies raised against the schwannoma factor will block the neuritepromoting activities of both the schwannoma factor and laminin. By rotary shadowing electron microscopy the schwannoma factor preparation exhibits cross-shaped images similar but not identical to those previously reported for rat and mouse laminin. In addition, the schwannoma factor preparation contains images resembling proteoglycans.
\end{abstract}

Received Novernber 5, 1984; Revised Februan; 12, 1985;

Accepted February 21, 1985

\footnotetext{
${ }^{1}$ We would like to thank Dr. Erkki Ruoslahti for critical comments on the manuscript and Eleanore Hewitt and George Klier for excellent technical assistance. This work was supported in part by National Institutes of Health Grant NS-16349 (S. V.) and National Institute of Arthritis and Metabolic Diseases Grant AM 30051 (E. E.). G. E. D. is supported by Medical Scientist Training Program, United States Public Health Service Grant GM-07198.

${ }^{2}$ To whom correspondence should be addressed.
}

These results suggest that the schwannoma factor may contain a distinct laminin molecule that associates with a proteoglycan.

The degree to which embryonic neurons will regenerate neurites in vitro can be regulated by at least two distinct types of growth tactors, namely, neuronotrophic (or survival factors) and substratumbinding, neurite-promoting factors (Varon and Adler, 1981; Manthorpe and Varon, 1985). The latter group of agents has been found in conditioned medium from various cell cultures (Collins, 1978; Adler and Varon, 1981; Adler et al., 1981; Coughlin et al., 1981; Lander et al., 1982, 1983; Matthew and Patterson, 1983) and recently in wound fluid surrounding regenerating peripheral nerve (Longo et al., 1984), and are particularly potent neurite-promoting factors when bound to polycationic substrata such as polyornithine. More recently, several groups have reported that the extracellular matarix proteins, laminin (LN) (Chung et al., 1979; Timpl et al., 1979) and fibronectin (FN) (Ruoslahti et al., 1982), have neurite-promoting influences when they are substratum bound (Akers et al., 1981; Baron von Evercooren et al., 1982; Manthorpe et al., 1983; Rogers et al., 1983; Wewer et al., 1983). We have previously described the partial purification of a polyornithine-binding, neurite-promoting factor (PNPF) from rat RN22 schwannoma cell conditioned medium (Manthorpe et al., 1981), the activity of which (unlike that of LN) was not blocked by the addition of antibodies to rat LN (Manthorpe et al., 1983). Here, we report on the purification and partial characterization of the rat schwannoma PNPF. We provide evidence that this factor contains LN molecules that may have proteoglycan-like molecules associated with them. Portions of this work have been published previously in abstract form (Davis et al., 1984).

\section{Materials and Methods}

Materials. The following reagents were obtained from Sigma Chemica Co. (St. Louis, MO): Trizma base, cesium chloride, guanidine hydrochloride, dextran blue 2000, thyroglobulin, ferritin, 4-chloro-1-napthol, protein A-agarose, Tween 20, bovine serum albumin (BSA), and 2-mercaptoethanol.

Methods. Rat RN22 schwannoma cells (initially obtained from Dr. S. E. Pfeiffer, University of Connecticut, Farmington, CT) were grown for 5 days to confluence in 100-mm tissue culture plates (Corning Glass Works, Corning, NY) using Dulbecco's modified essential medium supplemented with $5 \%$ fetal calf serum, $5 \%$ newborn calf serum, and $5 \%$ horse serum $(10 \mathrm{ml}$ of culture media/plate) (all sera were purchased from Irvine Scientific, Irvine, $\mathrm{CA}$ ). The growth medium was collected and centrifuged at $500 \times \mathrm{g}$ for 30 min and stored frozen at $-20^{\circ} \mathrm{C}$.

Bioassays and immunoblocking assays for PNPF activity were carried out as previously described (Manthorpe et al., 1981, 1983) using microcultures of ciliary ganglion neurons from 8-day chick embryos. A neurite-promoting unit (NPU) has been defined previously (Manthorpe et al., 1981) as the activity present in $1 \mathrm{ml}$ of culture medium that confers to polyornithine a halfmaximal neuritic effect after $24 \mathrm{hr}$ of culture. 

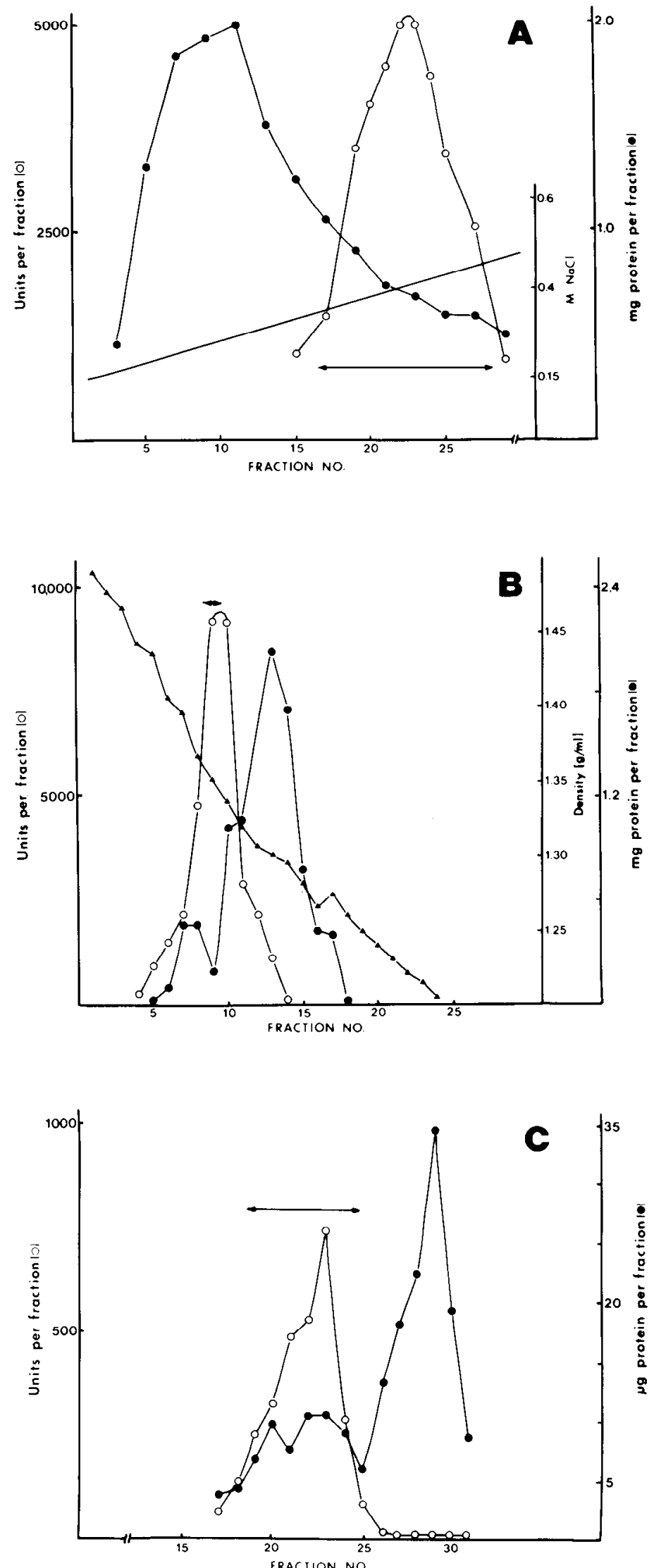

Figure 1. A, DE52; ion exchange chromatography of crude RN22 schwannoma conditioned medium. - total protein per fraction; $O$, total neurite promoting units per fraction. Fraction volumes $=5 \mathrm{ml}$. $B$, Cesium chloride equilibrium gradient centrifugation of the DE52 pool.
One and one-half liters of the schwannoma growth medium were loaded on a $30-\mathrm{ml}$ packed bed of a Whatman DE52 ion-exchange column $(2.8 \times$ $5.7 \mathrm{~cm}$ ) at a flow rate of $300 \mathrm{ml} / \mathrm{hr}$. The column was washed with $500 \mathrm{ml}$ of $150 \mathrm{~mm} \mathrm{NaCl}$ in $10 \mathrm{~mm}$ phosphate-buffered saline (PBS; pH 8) followed by a $300-\mathrm{ml}$ linear salt gradient from 150 to $600 \mathrm{~mm} \mathrm{NaCl}(300 \mathrm{ml}$ total gradient volume). The peak of PNPF activity that begins to elute at $0.3 \mathrm{M} \mathrm{NaCl}$ in the gradient was collected ( 110 to $200 \mathrm{ml}$ of gradient volume) and concentratcd to $4.5 \mathrm{ml}$ using an XM100 membrane in an ultrafiltration device (Amicon Corp., Danvers, MA). A precipitate developed and was removed by centrifugation at $10,000 \times \mathrm{g}$ for $10 \mathrm{~min}$, and the supernatant was dialyzed exhaustively against $0.4 \mathrm{M}$ guanidine hydrochloride in $50 \mathrm{mM}$ Tris- $\mathrm{HCl}(\mathrm{pH}$ $7.5)$ buffer. This was made $0.4 \mathrm{gm} / \mathrm{ml}$ by adding solid cesium chloride ( $\mathrm{CsCl}$; starting density $=1.3 \mathrm{gm} / \mathrm{ml}$ ), and the mixture was centrifuged at 180,000 $\times g$ for $48 \mathrm{hr}$ (Lander et al., 1982). The gradient fraction (150 $\mu$ l) containing the peak of PNPF activity (density $=1.35 \mathrm{gm} / \mathrm{ml}$ ) was dialyzed exhaustively against PBS, loaded on a 5-ml 20 to $40 \%$ sucrose gradient (in PBS), and centrifuged for $6 \mathrm{hr}$ at $300,000 \times \mathrm{g}$. The fractions $(150 \mu \mathrm{l})$ with peak activity were collected and pooled (about $750 \mu \mathrm{ll}$ ). For the molecular weight estimation of PNPF, a Sepharose 4B column (Pharmacia, Piscataway, NJ; $0.9 \times 150$ $\mathrm{cm}$ ) was equilibrated in $0.4 \mathrm{M} \mathrm{NaCl}, \mathrm{pH} 8.0$, and eluted at a flow rate of 8 $\mathrm{ml} / \mathrm{hr}$. Laminin was purified from rat yolk sac tumor extracts as described by Engvall et al. (1983). Rat plasma fibronectin was purified according to the method of Ruoslahti et al. (1982). Protein was determined by the method of Lowry et al. (1951) using BSA as the standard.

Enzyme-linked immunoassays (ELISAs) (Engvall, 1980) were performed using polyornithine-coated tissue culture plastic wells instead of polystyrene. Puritied rat LN and the ditterent PNPF fractions were serially diluted in PBS and allowed to bind to the wells at $37^{\circ} \mathrm{C}$ for $2 \mathrm{hr}$. The solutions were then aspirated and the wells were blocked overnight at $4^{\circ} \mathrm{C}$ with $0.1 \%$ Tween 20 , $1 \%$ BSA in PBS. The primary antibodies tested were added ( $50 \mu \mathrm{l} /$ well; antirat FN, 1:500; anti-rat LN, 1:500; anti-human LN, 1:250; anti-PNPF, 1:500) for $2 \mathrm{hr}$ at $37^{\circ} \mathrm{C}$. The wells were then washed five times with $100 \mu \mathrm{l}$ of Tween 20-BSA, and $50 \mu \mathrm{l}$ of a 1:1000 dilution of peroxidase-conjugated goat antirabbit antibody (Cappel Laboratories, West Chester, PA) was added for $1 \mathrm{hr}$ at $25^{\circ} \mathrm{C}$. Each well was washed six times with $100 \mu \mathrm{l}$ of Tween 20-BSA and reacted with $100 \mu \mathrm{l}$ of $O$-phenylenediamine at $1 \mathrm{mg} / \mathrm{ml}$ in $0.01 \% \mathrm{H}_{2} \mathrm{O}_{2}$ and $0.1 \mathrm{M}$ citrate phosphate buffer, $\mathrm{pH} 5.0$, for $15 \mathrm{~min}$. The optical density at 492 $\mathrm{nm}$ was determined and $L N$ immunoreactivity was calculated using a rat $L N$ standard curve.

Immunosequestration assays were performed by first adding $100 \mu \mathrm{l}$ of straight antiserum to $200 \mu \mathrm{l}$ of protein A-agarose gel and incubating with intermittent mixing for $1 \mathrm{hr}$ at $25^{\circ} \mathrm{C}$. The resulting antibody-coated beads were washed several times with PBS and then incubated with samples of PNPF or $L N(200 \mu \mathrm{l}$ at $100 \mathrm{NPU} / \mathrm{ml})$. The tubes were mixed frequently (10 to $15 \mathrm{~min}$ ) for $3 \mathrm{hr}$ at $25^{\circ} \mathrm{C}$. The resulting supernatants were then assayed for residual neurite-promoting activity.

Sodium dodecyl sulfate (SDS) gel electrophoresis was carried out using the method of Laemmli (1970) for $7.5 \%$ acrylamide gels or by the method of Blattler et al. (1972) for 2 to $10 \%$ acrylamide gradient gels, and the gels were stained with Coomassie blue. Molecular weight standards for gels were from Bethesda Research Laboratories (Gaithersburg, $M D$ ): myosin (H-chain), 200 kD; phosphorylase B, 92.5 kD; BSA, 68 kD; ovalbumin, 43 kD; $\alpha$ chymotrypsinogen, $25.7 \mathrm{kD} ; \beta$-lactoglobulin, $18.4 \mathrm{kD}$. Unstained proteins were transferred electrophoretically to nitrocellulose by the method of Towbin - et al. (1979). The immunoperoxidase technique (Towbin et al., 1979) employed a 1:500 dilution of antisera for non-immune, anti-FN, anti-rat $L N$, and anti-PNPF and a 1:200 dilution of anti-human LN sera. The peroxidaseconjugated secondary antibodies were added at a 1:1000 dilution. 4-Chloro1-napthol initially dissolved in methanol was made $0.5 \mathrm{mg} / \mathrm{ml}$ in PBS, stirred for $30 \mathrm{~min}$, and filtered; then, $\mathrm{H}_{2} \mathrm{O}_{2}$ was added to $0.005 \%$ and the mixture was used as the peroxidase reactant.

Rabbit antibodies to PNPF were obtained by injecting $500 \mu \mathrm{g}$ of partially \% purified PNPF (after DE52) subcutaneously four times at 3-week intervals. The first two injected preparations contained complete Freund's adjuvant, whereas the last two contained incomplete adjuvant. Rabbits were bled 1 week after the last injection. Purified rat LN from yolk sac tumor and rabbit antibodies to rat $\mathrm{FN}$ and $\mathrm{LN}$ and human $\mathrm{LN}$ were prepared as described (Engvall et al., 1983; Wewer et al., 1983).

fraction; $\mathrm{O}$, total neurite promoting units per fraction; $\boldsymbol{\Lambda}$, density in grams per milliliter. Fraction volumes $=150 \mu \mathrm{l}$. C. Sucrose density gradient (20 to $40 \%)$ centrifugation of the cesium chloride peak fraction. - total protein per fraction; $O$, total neurite promoting units per fraction. Fraction volumes $=$ $150 \mu \mathrm{l}$. The arrows in each figure indicate the fractions taken from each purification step. 
Electron microscopy was performed on the purified PNPF preparation as previously described (Engel et al., 1981). The sample was diluted to 10 to $30 \mu \mathrm{g}$ of protein $/ \mathrm{ml}$ in $0.2 \mathrm{M}$ ammonium acetate, mixed with an equal volume of glycerol, and sprayed onto freshly cleaved mica discs. The samples were then evacuated in an Edwards 306 vacuum evaporator and shadowed with platinum on a rotary stage at an angle of 6 to $9^{\circ}$, followed by carbon coating at $90^{\circ} \mathrm{C}$. The samples were examined in an Hitachi $\mathrm{H}-600$ electron microscope.

\section{Results}

\section{Purification of schwannoma neurite-promoting factor}

Rat schwannoma neurite-promoting factor was purified from serum-containing growth medium in three steps: (i) DE52 ion exchange chromatography, (ii) cesium chloride equilibrium gradient centrifugation, and (iii) sucrose density gradient centrifugation (see "Materials and Methods" and Fig. 1). The schwannoma cells produce approximately 5-fold more PNPF activity when cultured in the presence of serum than in serum-free medium (not shown). Because of the strong affinity of PNPF for the ion exchanger (Manthorpe et al., 1981), most of the scrum protcins were eliminated in the first step, making it unnecessary to use the serum-free conditioned medium employed previously. Table I shows the total PNPF units, protein amounts, and specific activities of the different fractions obtained during the purification. The pool from sucrose density centrifugation yielded $60 \mu \mathrm{g}$ of protein with a specific activity of $21,000 \mathrm{NPU} / \mathrm{mg}$ of protein

\section{Characterization of schwannoma neurite-promoting factor}

\section{Molecular weight determinations}

The puritied PNPF traction was applied to a Sepharose 4B column where the neurite-promoting activity eluted as a broad peak corresponding to an $M_{r}$ of $\sim 200,000$ (Fig. 2). The sucrose gradient fraction run on an SDS-polyacrylamide gel $(7.5 \%)$ under reducing conditions contained a major band at $200 \mathrm{kD}$ and two minor bands at 130 and $35 \mathrm{kD}$ (Fig. 3). For comparison, purified rat LN exhibited two bands at 400 and $200 \mathrm{kD}$. The 200-kD band of PNPF but not that of I. N resolved into a doublet band at $200 \mathrm{kD}$ on a 2 to $10 \%$ gradient gel system (not shown). Under non-reducing conditions, PNPF also showed doublet bands at $900 \mathrm{kD}$ that migrated slightly faster than those of LN (see below).

Immunoreactivity of schwannoma neurile-promoting factor with antibody directed against rat $L N$

Enzyme-linked immunoassay (ELISA). Both the rat schwannoma PNPF preparation and rat LN contain a 200-kD subunit, and we have recently reported (Davis et al., 1985) that both factors have identical influences on several parameters of ciliary neuritic growth. Therefore, it became important to compare the two proteins in more detail. A standard ELISA procedure (Engvall, 1980) was modified to use polyornithine-coated tissue culture plastic wells in order to mimic the

TABLE I

Purification of schwannoma neurite-promoting factor ${ }^{a}$

\begin{tabular}{lcccrr}
\hline \multicolumn{1}{c}{ Sarniple } & Total Urils & Starting Units $(\%)$ & Total Protein (mg) $^{b}$ & Units/mg & Fold Purification \\
\hline $\begin{array}{l}\text { Crude conditioned medium } \\
\quad(1.5 \text { litcrs) }\end{array}$ & 76,000 & 100 & 13,900 & 5.5 & 1 \\
DE52 pool & 33,200 & 44 & 8.4 & 3,950 & 720 \\
Cesium chloride peak & 5,800 & 7.6 & 0.46 & 12,600 & 2,290 \\
Sucrose density pool & 1,260 & 1.7 & 0.06 & 21,000 & 3,820 \\
\hline
\end{tabular}

${ }^{a}$ All values are averages from two different preparations.

${ }^{\circ}$ Determined by the method of Lowry et al. (1951).

Figure 2. Sepharose 4B elution profile of PNPF activity $(\mathrm{O})$. Molecular weight standards were Dextran Blue $2000(2,000,000)$. thyroglobulin $(670,000)$, and Ferritin $(440,000)$. Fraction volumes $=2.4 \mathrm{ml}$.






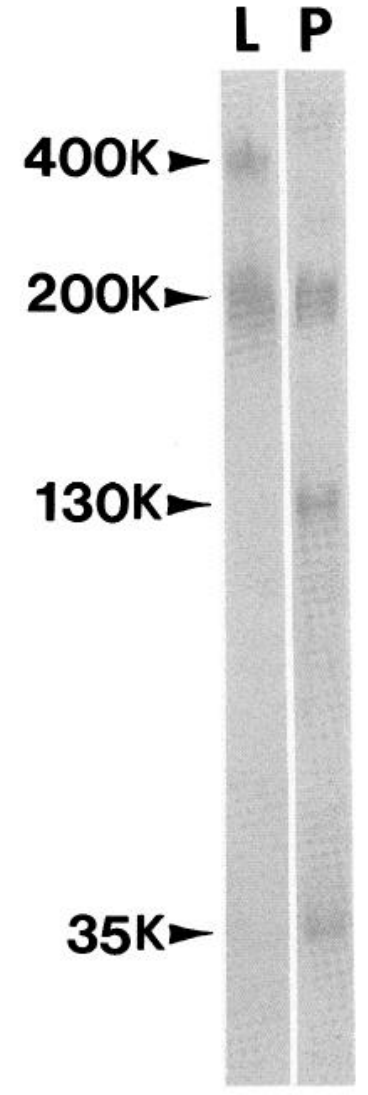

Figure 3. SDS-PAGE of purified PNPF and LN. Ten micrograms of either rat $L N(L)$ or PNPF $(P)$ from the sucrose gradient pool were electrophoresed on a $7.5 \%$ polyacrylamide gel and stained with Coomassie blue. neurite-promoting factor biological assay as closely as possible. Using ELISA with antisera raised against rat laminin, the schwannoma neurite-promoting activity is shown to co-purify with $\mathrm{LN}$ immunoreactivity (Table II). Also, samples from all four purification steps had very comparable NPUs per milligram of LN antigen, suggesting that the activity was associated with an LN-immunoreactive protein. Note also that the specific activity of schwannoma PNPF appears to be 3- to 4-fold greater than that of purified rat LN. The reason for this difference is not clear but may be related to (i) the total percentage of biologically active versus immunologically reactive molecules in each preparation or (ii) the proportion of biologically active molecules that bind to the PORN substratum in a biologically active orientation. Rabbit antisera directed against large fragments of human LN (Wewer et al., 1983) or against partially purified PNPF also reacted against PNPF and LN by ELISA whereas nonimmune and anti-FN sera did not (data not shown).

Immunoblotting. Rat schwannoma PNPF and rat $\mathrm{LN}$ were found to react by immunoblotting with antisera raised against rat and human $L N$ and rat PNPF (Fig. 4). These three antisera stained the $200-\mathrm{kD}$ band in the PNPF lane and both the $400-$ and $200-\mathrm{kD}$ bands in the LN lane. The anti-PNPF sera recognized another band in the PNPF preparation with an $M_{\mathrm{r}}$ in the range of 130,000 to 160,000 . Fibronectin stained with anti-FN but not with the other antibodies. PNPF and LN were also electrophoresed on 2 to $10 \%$ polyacrylamide gels under non-reducing conditions and transferred to nitrocellulose. A doublet band at about $900 \mathrm{kD}$ was seen which migrated slightly faster than non-reduced LN (Fig. 5). These data show that the 200kD subunits of PNPF are disulfide linked as are the subunits of LN. Other weak-staining bands were visualized in the PNPF ( 110 and 50 $\mathrm{kD})$ and $\mathrm{LN}(1,200,120$, and $50 \mathrm{kD})$ lanes without 2-mercaptoethanol. These bands may represent minor aggregated molecules (1200 $k D$ ), proteolytic fragments of $L N$, or minor contaminant bands recognized by the anti-LN antisera.

Immunosequestration and immunoblocking. The association between $\mathrm{LN}$ immunoreactivity and the neurite-promoting activity of

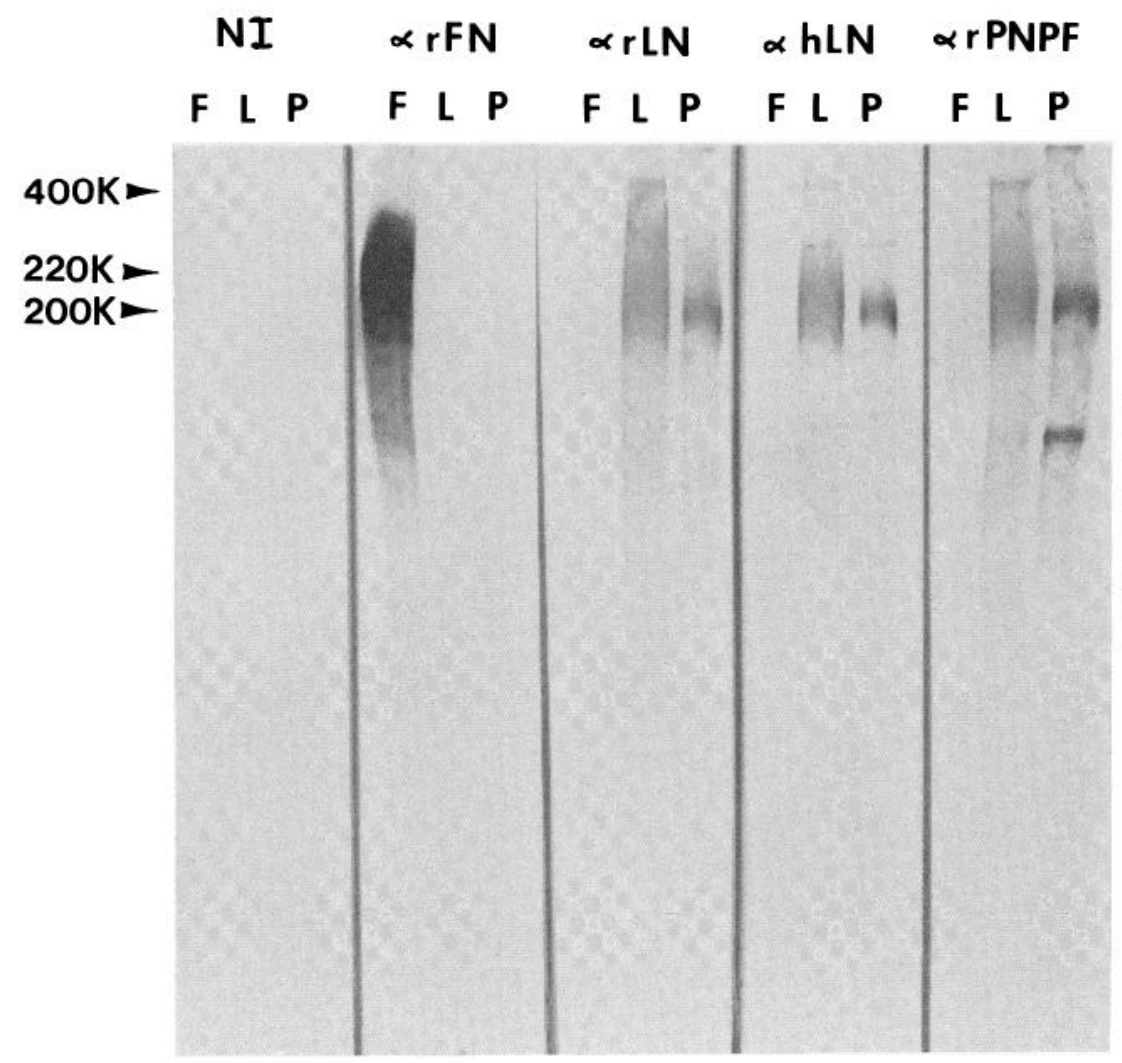

Figure 4. Immunoblots after SDS-PAGE (7.5\% polyacrylamide) of FN $(F), L N(L)$, and PNPF $(P)$. One microgram of each protein was loaded per lane and the blots were stained using the following rabbit sera: nonimmune $(1: 200)$, anti-rat FN (1:500), anti-rat LN (1:500), anti-human LN (1:200), and anti-rat PNPF (1:500). Sera were added for 4 $\mathrm{hr}$ at $25^{\circ} \mathrm{C}$, the blots were treated with a $1: 1000$ dilution of peroxidase-conjugated goat anti-rabbit immunoglobulin for $2 \mathrm{hr}$ at $25^{\circ} \mathrm{C}$, and then the blots were reacted for peroxidase activity using chloronapthol. 
TABLE ॥

Co-purification of schwannoma neurite-promoting factor with LN immunoreactivity ${ }^{\text {a }}$

\begin{tabular}{|c|c|c|c|c|c|}
\hline Sample & Total LN $(\mathrm{mg})^{b}$ & Starting LN (\%) & Units ${ }^{c} / \mathrm{mg}$ of $\mathrm{LN}$ & $\mathrm{LN}(\mathrm{mg}) / \mathrm{mg}$ of Protein ${ }^{\alpha}$ & Fold Purification \\
\hline $\begin{array}{l}\text { Crude conditioned medium } \\
\text { (1.5 liters) }\end{array}$ & 5.0 & 100 & 15,200 & 0.0004 & 1 \\
\hline DE52 pool & 1.5 & 30 & 22,130 & 0.18 & 450 \\
\hline Sucrose pool & 0.074 & 1.5 & 17,030 & 1.23 & 3,075 \\
\hline Rat LN & & & 6,000 & 1.0 & \\
\hline
\end{tabular}

${ }^{a}$ Values are averages from two different PNPF preparations.

${ }^{b}$ Determined by sandwich ELISA using polyornithine-coated culture plastic substrata (see "Materials and Methods").

${ }^{c}$ Neurite promoting units-see data in Table I.

${ }^{d}$ Determined by the method of Lowry et al. (1951).

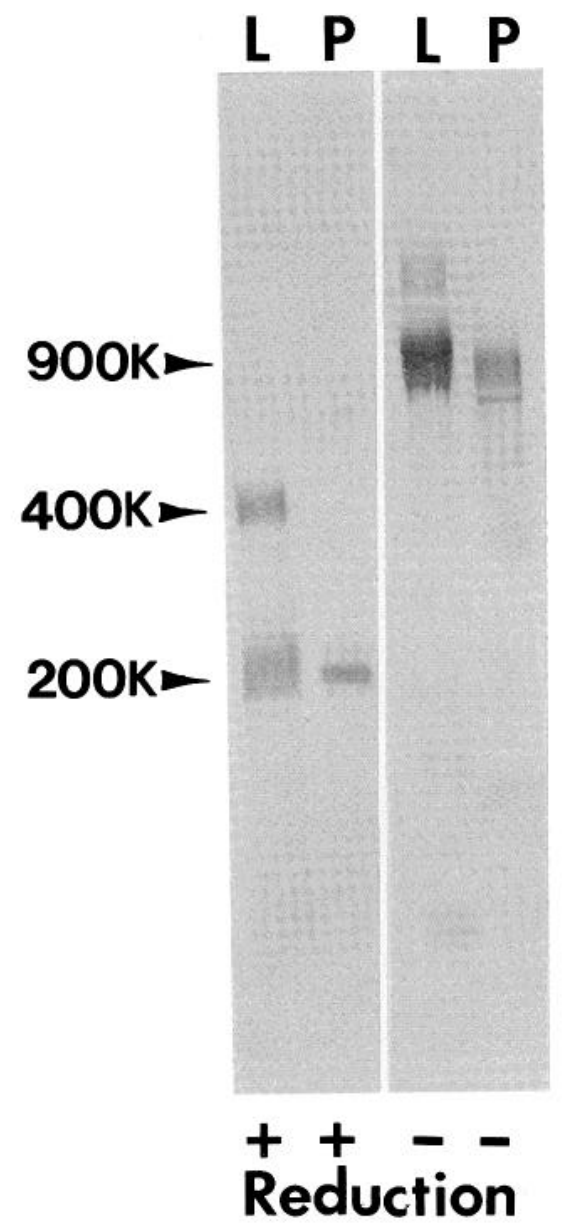

Figure 5. Immunoblots after SDS-PAGE (2 to $10 \%$ linear polyacrylamide gradient) of $L N(L)$ and PNPF $(P)$. One microgram of protein was loaded per lane with $(+)$ and without $(-)$ previous reduction with 2-mercaptoethanol. Anti-rat laminin (1:500) sera were added for $4 \mathrm{hr}$ at $25^{\circ} \mathrm{C}$, the blots were treated with a 1:1000 dilution of peroxidase-conjugated goat anti-rabbit immunoglobulin for $2 \mathrm{hr}$ at $25^{\circ} \mathrm{C}$, and then the blots were reacted for peroxidase activity using chloronapthol.

schwannoma PNPF was further examined using immunosequestration and immunoblocking assays (Table III). Both the PNPF and LN activities were quantitatively removed from solution by anti-rat $L N$, anti-human $\mathrm{LN}$, and anti-PNPF antibodies bound to protein A-agarose beads. Nonimmune and anti-FN sera had no effect. In immunoblocking assays, anti-rat LN sera were found to abolish rat laminin activity while having little effect on the purified PNPF activity. Interestingly, anti-PNPF sera partially blocked both LN and PNPF activity and consistently blocked more of the laminin activity. This antiserum recognized a $130-\mathrm{kD}$ band in the PNPF preparation (see Fig. 4) that
TABLE III

Influence of different antisera on schwannoma PNPF and $L N$ activities For the immunosequestration assay, $100 \mu \mathrm{l}$ of each antiserum were incubated with protein A-agarose beads $(200 \mu \mathrm{l})$ and then incubated with PNPF or LN (diluted to $100 \mathrm{NPU} / \mathrm{ml}$ ) for $3 \mathrm{hr}$ at $25^{\circ} \mathrm{C}$. Unbound proteins were then tested for activity. For the immunoblocking assay, serially diluted PNPF or LN was allowed to bind to polyornithine-coated wells for $2 \mathrm{hr}$ at $37^{\circ} \mathrm{C}$. The various antisera were then added at a 1:50 dilution in PBS to the PNPF and $\mathrm{LN}$-coated wells, the plates were incubated for $2 \mathrm{hr}$ at $37^{\circ} \mathrm{C}$, and the wells were assayed for neurite-promoting activity. A neurite-promoting titer (see "Materials and Methods") was then determined for each sample and calculated as a percentage with respect to the nonimmune serum control (both PNPF and LN samples had a titer of $500 \mathrm{NPU} / \mathrm{ml}$ in the immunoblocking control).

\begin{tabular}{|c|c|c|c|c|}
\hline \multirow{3}{*}{ Antisera } & \multicolumn{4}{|c|}{ Percentage of Total Units Remaining } \\
\hline & \multicolumn{2}{|c|}{ Immunosequestration } & \multicolumn{2}{|c|}{ Immunoblocking } \\
\hline & PNPF & $\mathrm{LN}$ & PNPF & $\mathrm{LN}$ \\
\hline Nonimmune & 100 & 100 & 100 & 100 \\
\hline Rat FN & 110 & 120 & 102 & 103 \\
\hline Human LN & 4 & 30 & 90 & 92 \\
\hline Rat LN & 3 & 3 & 91 & 0 \\
\hline Partially purified rat PNPF & 2 & 3 & 52 & 30 \\
\hline
\end{tabular}

the anti-LN did not, suggesting that this subset of antibodies could be related to its partial blocking effects against PNPF. Anti-human $\mathrm{LN}$, anti-FN, and nonimmune sera had little or no blocking effect on either factor.

\section{Electron microscopic examination of schwannoma PNPF}

Purified mouse, rat, and human LN have previously been visualized by the rotary shadowing method using electron microscopy (Engel et al., 1981; Engvall et al., 1983; Wewer et al., 1983). Both mouse and rat $\mathrm{LN}$ are cross-shaped molecules containing three short arms and one long arm. Purified proteins from pepsin digests of human $\mathrm{LN}$ which collectively exhibit neurite-promoting activity (Wewer et al., 1983) were shown to have mostly intact long arms and one or more short arms that were usually truncated. Rotary shadowing of PNPF (Fig. 6) suggests it to be an LN molecule possessing intact long arms and usually two short arms. Occasional images appeared to have a complete LN structure although these were rather infrequent. Also observed in this preparation were large images resembling proteoglycans (Fig. 7) (Fujiwara et al., 1984; see Fig. 8). The proportion of $L N$ and proteoglycan-like images appeared to be approximately $1: 1$ in the fields observed. Each of the proteoglycan-like structures appeared to possess a central core region and many arms radiating from it. The $\mathrm{LN}$ and proteoglycan-like images observed in the electron micrographs occasionally appeared to be associated (Fig. 8). In the cases where an interaction was seen, the proteoglycan-like structures appeared to be associated with the short arm region of LN. Also observed in the PNPF preparation were images with thin strands of material emanating from a 


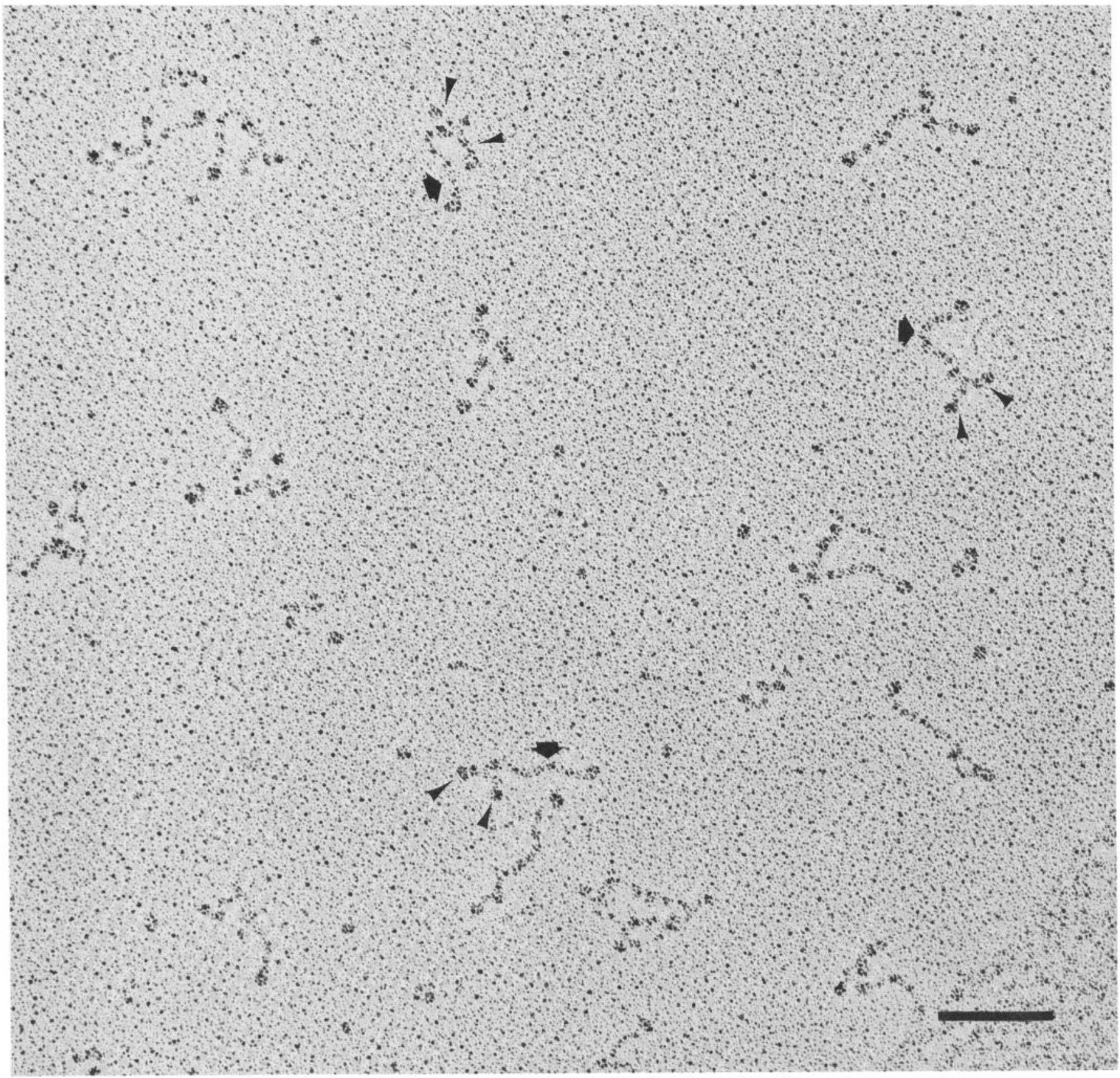

Figure 6. Electron micrograph showing a representative field of rotary-shadowed schwannoma PNPF. The thick arrows show the long arm and the thin arrowheads show the short arms of LN-like cross-shaped images. Bar $=100 \mathrm{~nm}$.

region around the intersection of the short and long arms (Fig. 8 , middle panel). The nature of these strands is unknown, although they may represent an altered LN short arm or the attachment (covalent or noncovalent) of another protein or glycosaminoglycan to this region.

\section{Discussion}

We report here on the similarities and differences between two neurite-promoting proteins: one from a rat schwannoma tumor cell conditioned medium and another from rat yolk sac tumor extracts. Both purified proteins share the following properties: $(i)$ they copurify with LN immunoreactivity monitored by ELISA; (ii) their associated neurite-promoting activities are immunosequestered by immobilized antibodies raised against rat and human $\mathrm{LN}$ and against partially purified schwannoma PNPF; (iii) they both have a 200-kD subunit on SDS polyacrylamide gels run under reducing conditions and a $900-\mathrm{kD}$ band run under non-reducing conditions; (iv) by immunoblotting the 200- and 900-kD bands stain with antibodies raised against rat $L N$ and schwannoma PNPF; $(v)$ the neuritepromoting activities of LN and PNPF are blocked by antibodies raised against PNPF; and (vi) by rotary shadowing electron microscopy, the PNPF preparation contains predominantly cross-shaped images resembling previously described images of $L N$ (Engel et al. 1981).

The schwannoma PNPF differs from rat LN in that it: $(i)$ does not possess a $400-\mathrm{kD}$ but does contain 130- and 35-kD polypeptides on SDS-polyacrylamide gels run under reducing conditions; (ii) contains neurite-promoting activity which is not blocked by anti-rat 


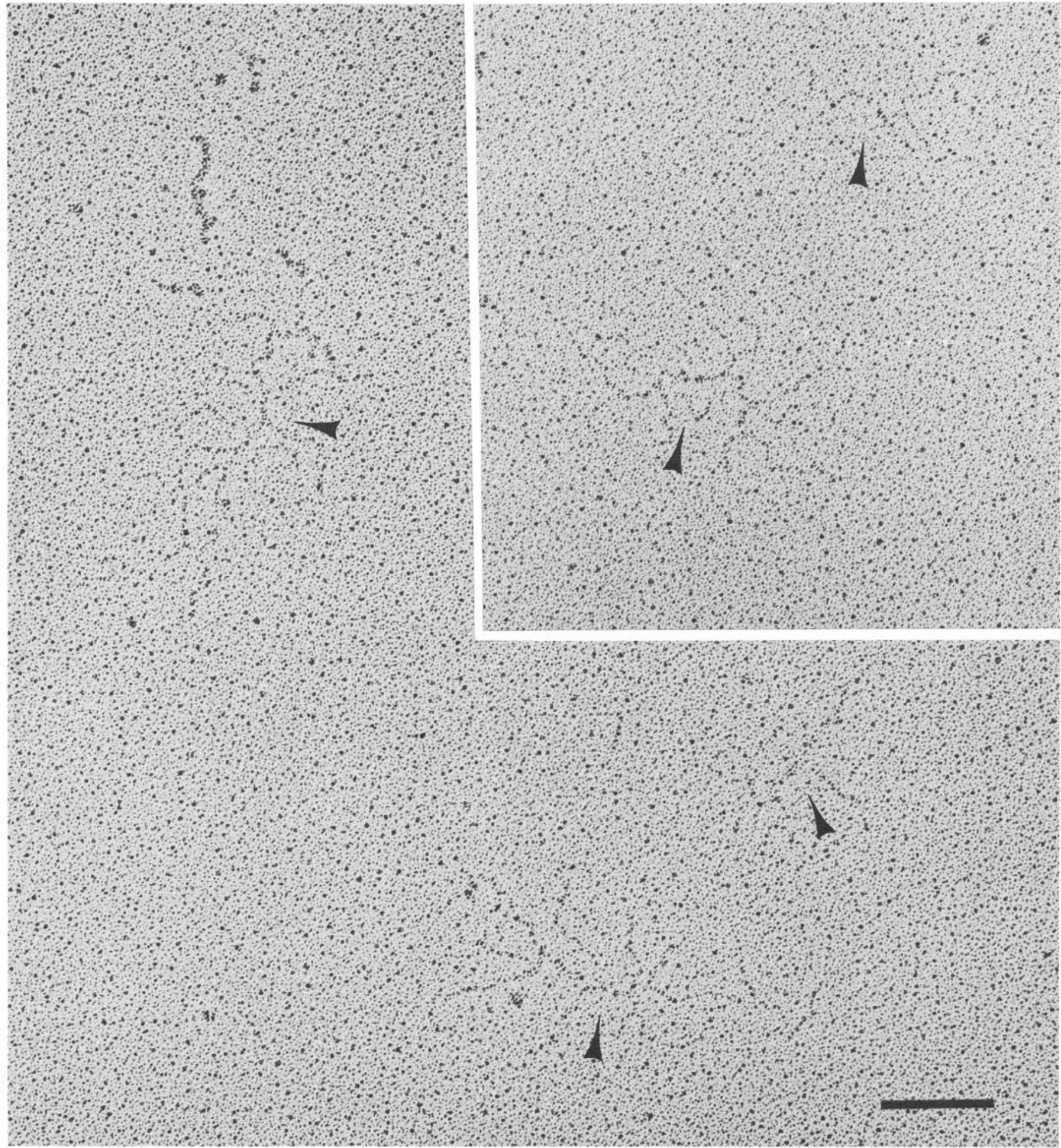

Figure 7. Electron micrograph showing selected proteoglycan-like molecules of rotary-shadowed schwannoma PNPF. The two panels contain a total of five proteoglycan-like images shown by arrowheads. Bar $=100 \mathrm{~nm}$.

LN sera; and (iii) reveals cross-shaped images by electron microscopy which are composed of one long arm and possibly only two short arms rather than one long arm and three short arms as reported for both mouse and rat LN (Engel et al., 1981; Engvall et al., 1983). The schwannoma PNPF preparation also contains images resembling proteoglycans (Fujiwara et al., 1984) which occasionally appear to be associated with the cross structure of laminin.

The very acidic behavior on DE52 ion exchange columns as well as the high buoyant density $(1.35 \mathrm{gm} / \mathrm{ml})$ on cesium chloride gradients suggests that the schwannoma neurite-promoting activity might contain proteoglycan. However, further studies will be required to resolve this point. Lander et al. $(1982,1983)$ and Matthew and Patterson (1983) have reported that neurite-promoting factors from bovine corneal endothelial and pheochromocytoma cell conditioned medium, respectively, are associated with heparan sulfate proteoglycan. 

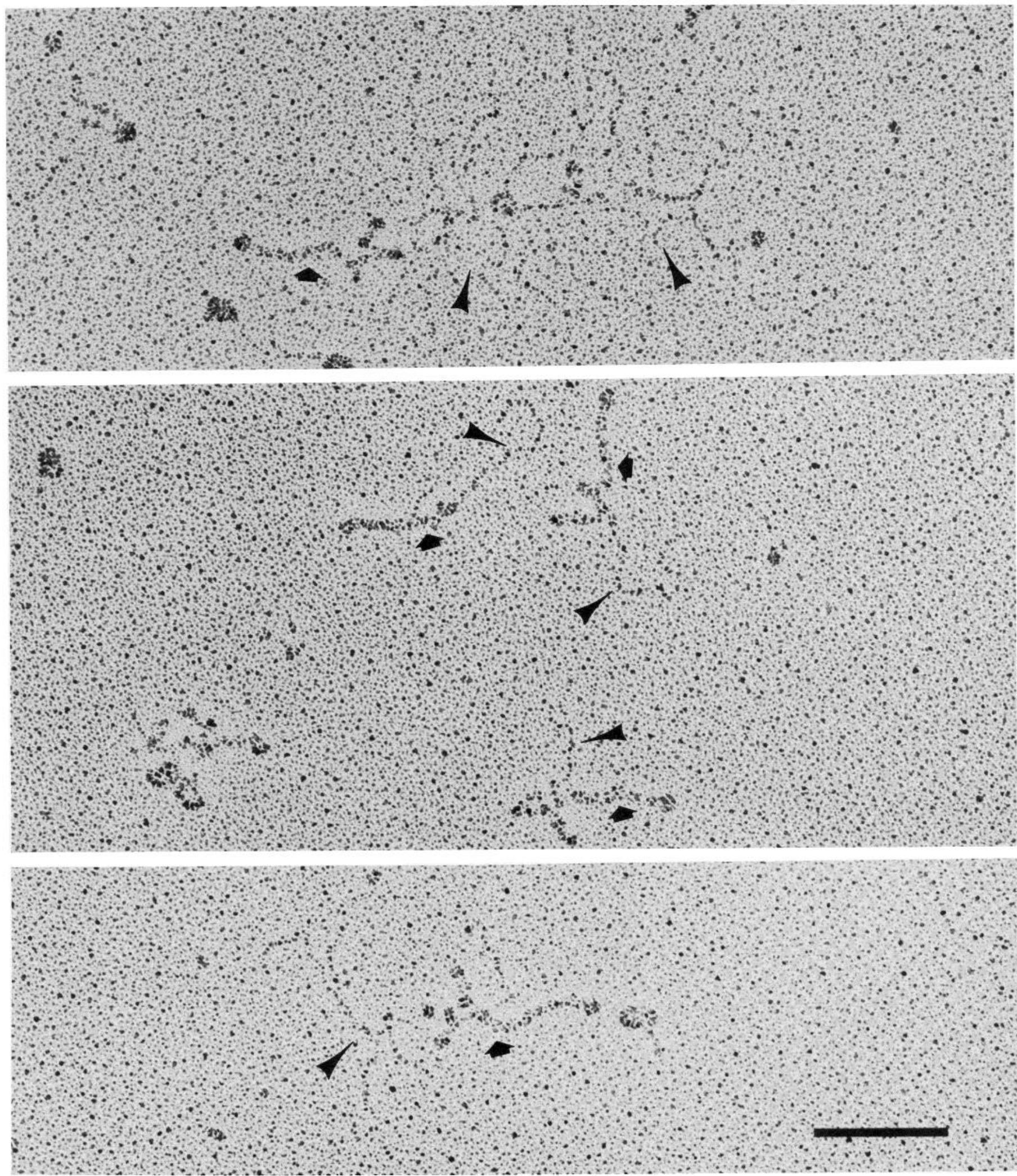

Figure 8. Electron micrographs showing selected examples of the apparent association between LN-like (short arrows) and proteoglycan-like (long arrowheads) molecules in rotary-shadowed schwannoma PNPF. The middle panel shows three LN-like images with a thin strand (long arrowheads) apparently linked at the intersection of the short and long arms. Bar $=100 \mathrm{~nm}$.

Laminin has previously been shown by affinity chromatography to bind heparin and glycosaminoglycans (Sakashita et al., 1980; Del Rosso et al., 1981). Recently, Fujiwara et al. (1984) isolated a high density heparan sulfate proteoglycan from the mouse EHS sarcoma tumor which exhibited weak affinity for $\mathrm{LN}$ purified from the same source. None of the previously described interactions would appear 
to be strong enough to account for the stability (during the purification involving exposures to high salt and guanidine hydrochloride concentrations) of the putative schwannoma LN-proteoglycan complex described in this report (cf. Fig. 7). It remains possible that the schwannoma LN molecule (which has no 400-kD subunit and appears to have a structure by electron microscopy which is different from the other purified rodent LNs) may have an increased affinity for proteoglycans. Alternatively, proteoglycan or glycosaminoglycan chains may be covalently linked to the schwannoma larminin.

Laminin or laminin-like proteins have been shown to be present in conditioned media from various cell types. Palm and Furcht (1983) immunoprecipitated schwannoma cell conditioned medium with antiLN sera and, after SDS-PAGE with reduction, visualized 200 - and $150-\mathrm{kD}$ bands but no visible $400-\mathrm{kD}$ band. Without reduction, a band at $850 \mathrm{kD}$ was seen that co-migrated with LN. Such behaviors of $L N$ antigens in our schwannoma PNPF preparations are in agreement with these data. Other workers have also observed 200- and $150-\mathrm{kD}$ bands in anti-LN immunoprecipitates of conditioned medium from rat Schwann cells and from both myogenic and fibroblastic cultures from mouse skeletal muscle cells (Kuhl et al., 1982; Cornbrooks et al., 1983). However, the apparent absence of a 400-kD subunit may not be a general rule of LN isolated from conditioned medium, since Sakashita et al. (1980), Albrechtsen et al. (1981), and Kuhl et al. (1982) did visualize this subunit in mouse PF HR-9, human $\mathrm{FL}$, and rat $\mathrm{L} 6$ myoblast cell conditioned media, respectively.

Recently, several attempts have been made to identify the regions of $L N$ responsible for its neurite-promoting and cell attachment activities. Edgar et al. (1984) reported that polyclonal antibodies to a heparin-binding fragment derived from the end of the long arm of mouse $L N$ blocked the neurite-promoting activity of intact $L N$ bound to polyornithine-coated substrata. Previous reports concerning cell attachment domains of LN (Rao et al., 1982; Timpl et al., 1983) indicated that all of the activity was localized in fragments containing all or specific parts of the short arms. The cell attachment activities of intact $L N$ and several short arm-derived fragments of $L N$ were not blocked by antibodies raised against intact mouse LN (Timpl et al., 1983). Intriguingly, the purified schwannoma PNPF activity is also not blocked by anti-LN antibodies raised against intact rat LN. The explanation for this difference between PNPF and LN is not known at present. Among possible reasons for the resistance of schwannoma PNPF to anti-LN antibodies are: (i) structural differences underlying the absence of a 400-kD subunit and the distinctive short arm structure seen by electron microscopy, (ii) the binding of a proteoglycan to the $L N$ that may sterically interfere with the binding of $L N$-blocking antibodies, (iii) the presentation of a different $L N$ neurite-promoting active site if proteoglycan is associated, and (iv) the major neurite-promoting activity of schwannoma PNPF being expressed in an area of the LN molecule (i.e., short arms) distinct from that of purified $L N$ in the bioassay on polyornithine-coated substrata. The work described here establishes the basis for more detailed comparisons between the schwannoma factor and LN, and further experiments will likely lead to a better understanding of how $\mathrm{LN}$ is presented in an active form to promote nerve regeneration.

\section{References}

Adler, R., and S. Varon (1981) Neuritic guidance by polyornithine-attached materials of ganglionic origin. Dev. Biol. 81: 1-11.

Adler, R., M. Manthorpe, S. D. Skaper, and S. Varon (1981) Polyornithineattached neurite promoting factors (PNPFs). Culture sources and responsive neurons. Brain Res. 206: 129-144.

Akers, R. M., D. F. Mosher, and J. E. Lilien (1981) Promotion of retinal neurite outgrowth by substratum-bound fibronectin. Lev. Biol. 86: 179-188.

Albrechtsen, R., M. Nielsen, U. Wewer, E. Engvall, and E. Ruoslahti (1981) Basement membrane changes in breast cancer detected by immunohistochemical staining for laminin. Cancer Res. 41: 5076-5081.

Baron von Evercooren, A., H. K. Kleinman, S. Ohno, P. Marangos, J. P. Schwartz, and M. E. Dubois-Dalcq (1982) Nerve growth factor, laminin and fibronectin promote neurite growth in human fetal sensory ganglia cultures. J. Neurosci. Res. 8: 179-194.
Blattler, D. P., F. Garner, K. Van Slyke, and A. Bradley (1972) Quantitative electrophoresis in polyacrylamide gels of 2 to $40 \%$. J. Chromatogr. 64 . 147-155.

Chung, A. E., R. Jaffe, I. L. Freeman, J. Vergnes, J. E. Braginski, and B. Carlin (1979) Properties of a basement membrane-related glycoprotein synthesized in culture by a mouse embryonal carcinoma-derived cell line. Cell 16: 277-287

Collins, F. (1978) Induction of neurite outgrowth by a conditioned medium factor bound to culture substratum. Proc. Natl. Acad. Sci. U. S. A. 75 b210-5213.

Cornbrooks, C. J., D. J. Carey, J. A. McDonald, R. Timpl, and R. P. Bunge (1983) In vivo and in vitro observations on laminin production by Schwann cells. Proc. Natl. Acad. Sci. U. S. A. 80: 3850-3854.

Coughlin, M. D., E. M. Bloom, and I. B. Black (1981) Characterization of a neuronal growth factor from mouse heart-cell-conditioned medium. Dev. Biol. 82: 56-68.

Davis, G. E., M. Manthorpe, and S. Varon (1984) Purification of rat Schwannoma neurite promoting factor. Soc. Neurosci. Abstr. 10: 38.

Davis, G. E., M. Manthorpe, and S. Varon (1985) Parameters of neuritic growth from ciliary ganglion neurons in vitro: Influence of laminin, Schwannoma polyornithine-binding neurite promoting factor and ciliary neuronotrophic factor. Dev. Brain Res. 17: 75-84.

Del Rosso, M., R. Cappelletti, M. Viti, S. Vannucchi, and V. Chiarugi (1981) Binding of the basement membrane glycoprotein laminin to glycosaminoglycans. Biochem. J. 199: 699-704.

Edgar, D., R. Timpl, and H. Thoenen (1984) The heparin-binding domain of laminin is responsible for its effects on neurite outgrowth and neuronal survival. EMBO J. 3: 1463-1468

Engel, J., E. Odermatt, A. Engel, J. A. Madri, H. Furthmayr, H. Rohde, and R. Timpl (1981) Shapes, domain organizations and flexibility of laminin and fibronectin, two multifunctional proteins of the extracellular matrix. J. Mol. Biol. 150: 97-120.

Engvall, E. (1980) Enzyme immunoassay: ELISA and EMIT. Methods Enzymol. 70: 419-439.

Engvall, E., T. Krusius, V. Wewer, and E. Ruoslahti (1983) Laminin from rat yolk sac tumor: Isolation, partial characterization and comparison with mouse laminin. Arch. Biochem. Biophys. 222: 649-656.

Fujiwara, S., H. Wiedemann, R. Timpl, A. Lustig, and J. Engel (1984) Structure and interactions of heparan sulfate proteoglycans from a mouse tumor basement membrane. Eur. J. Biochem. 143: 145-157.

Kuhl, U., R. Timpl, and K. Von DerMark (1982) Synthesis of type IV collagen and laminin in cultures of skeletal muscle cells and their assembly on the surface of myotubes. Dev. Biol. 93: 344-354.

Laemmli, U. K. (1970) Cleavage of structural protein during the assembly of the head of bacteriophage T-4. Nature (Lond.) 227: 680-685.

Lander, A. D., D. K. Fujii, D. Gospodarowicz, and L. F. Reichardt (1982) Characterization of a factor that promotes neurite outgrowth. Evidence linking activity to a heparan sulfate proteoglycan. J. Cell Biol. 94: 574585.

Lander, A. D., K. Tomaselli, A. L. Calof, and L. F. Reichardt (1983) Studies on extracellular matrix components that promote neurite outgrowth. Cold Spring Harbor Symp. Quant. Biol. 48: 611-623.

Longo, F. M., E. G. Hayman, G. E. Davis, E. Ruoslahti, E. Engvall, M. Manthorpe, and S. Varon (1984) Neurite promoting factors and extracellular matrix components accumulating in vivo within nerve regeneration chambers. Brain Res. 309: 105-117.

Lowry, O. H., N. J. Rosebrough, A. L. Farr, and R. J. Randall (1951) Protein measurement with the Folin phenol reagent. J. Biol. Chem. 193: 265-275

Manthorpe, M., and S. Varon (1985) Regulation of neuronal survival and neuritic, growth in the avian ciliary ganglion by trophic, factors. In Growth and Maturation Factors, Vol. 3, G. Guroff, ed., pp. 77-117, John Wiley \& Sons, Inc., New York.

Manthorpe, M., S. Varon, and R. Adler (1981) Neurite-promoting factor (NPF) in conditioned medium from RN22 Schwannoma cultures. Bioassay, fractionation and other properties. J. Neurochem. 37: 759-767.

Manthorpe, M., E. Engvall, E. Ruoslahti, F. M. Longo, G. E. Davis, and S. Varon (1983) Laminin promotes neuritic regeneration from cultured peripheral and central neurons. J. Cell Biol. 97: 1882-1890.

Matthew, W. D., and P. H. Patterson (1983) The production of a monoclonal antibody that blocks the action of a neurite outgrowth-promoting factor Cold Spring Harbor Symp. Quant. Biol. 48: 625-631.

Palm, S. L., and L. T. Furcht (1983) Production of laminin and fibronectin by Schwannoma cells: Cell-protein interactions in vitro and protein localization in peripheral nerve in vivo. J. Cell Biol. 96: 1218-1226.

Rao, C. N., I. M. K. Margulies, T. S. Tralka, V. P. Terranova, J. A. Madri, and L. A. Liotta (1982) Isolation of a subunit of laminin and its role in molecular 
structure and tumor cell attachment. J. Biol. Chem. 257: 9740-9744.

Rogers, S. L., P. C. Letourneau, S. L. Palm, J. McCarthy, and L. T. Furcht (1983) Neurite extension by peripheral and central nervous system neurons in rcsponse to substratum-bound fibronectin and laminin. Dev. Biol. 98: 212-220.

Ruoslahti, E., E. G. Hayman, M. Pierschbacher, and E. Engvall (1982) Fibronectin: Purification, immunochemical properties, and biological activities. Methods Enzymol. 82: 803-831.

Sakashita, S., E. Engvall, and E. Ruoslahti (1980) Basement membrane glycoprotein laminin binds to heparin. FEBS Lett, 116: 243-246.

Timpl, R., H. Rohde, P. G. Robey, S. I. Rennard, J. -M. Foidart, and G. R. Martin (1979) Laminin-A glycoprotein from basement membranes. J. Biol. Chem. 254: 9933-9937.
Timpl, R., S. Johansson, V. Van Delden, I. Oberbaumer, and M. Hook (1983) Characterization of protease-resistant fragments of laminin mediating attachment and spreading of rat hepatocytes. J. Biol. Chem. 258: 89228927.

Towbin, H., T. Staehelin, and J. Gordon (1979) Electrophoretic transfer of proteins from polyacrylamide gels to nitrocellulose sheets: Procedure and some applications. Proc. Natl. Acad. Sci. U. S. A. 76: 4350-4354.

Varon, S., and R. Adier (1981) Trophic and specifying factors directed to neuronal cells. Adv. Cell. Neurobiol. 2: 115-163.

Wewer, U., R. Albrechtsen, M. Manthorpe, S. Varon, E. Engvall, and E. Ruoslahti (1983) Human laminin isolated in a nearly intact, biologically active form from placenta by limited proteolysis. J. Biol. Chem. 250 12654-12660. 